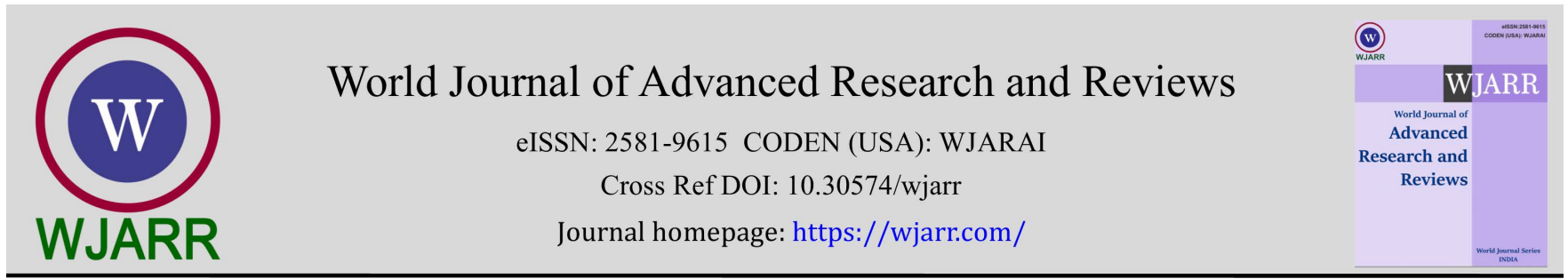

(RESEARCH ARTiCle)

Check for updates

\title{
Attacks by Termites (Blattoptera: Insecta) in cassava crops (Manioth esculenta Crantz.) in Daloa (Center-West, Côte d'Ivoire)
}

\author{
N'Guessan Lucie YEBOUE $1{ }^{\text {, }}$, Crolaud Sylvain TRA Bi ${ }^{1}$, Edouard KOUADIO 2 , Souleymane KONATE ${ }^{3}$ and Yao \\ TANO $^{3}$ \\ 1 Improvement and Agricultural Production Laboratory, UFR Agroforestry, Jean Lorougnon Guédé University, BP 150 \\ Daloa, Côte d'Ivoire. \\ 2 Biodiversity and Tropical Ecology Laboratory, UFR Environment, Jean Lorougnon Guédé University, BP 150 Daloa, Côte \\ d'Ivoire. \\ ${ }^{3}$ Plant Protection Laboratory, UFR Science of Nature, Nangui Abrogoua University, 02 BP 801 Abidjan 02, Côte d'Ivoire.
}

World Journal of Advanced Research and Reviews, 2021, 12(03), 458-465

Publication history: Received on 14 November 2021; revised on 19 December 2021; accepted on 21 December 2021

Article DOI: https://doi.org/10.30574/wjarr.2021.12.3.0709

\begin{abstract}
A study was carried out on the attack of termites in three cassava plots located in the zone of Daloa (town in the centerwest of the Côte d'Ivoire). The main objective of this study was to ensure a sustainable productivity of cassava in the Daloa region by controlling termite's pests of cassava crops according to the phenological stage, namely: the plot of cassava at the small stalk stage, the plot at the tuber production stage and the plot at the harvest stage. To this end, systematic excavations were carried out in the sections along the transects and plant-by-plant sampling in order to inventory the different species of termites on the plots and to highlight the damage they cause. This made it possible to identify 4 species of termites: Odontotermes sp., Macrotermes bellicosus, Pseudacanthotermes militaris and Nasutitermes latifrons, of which 1 species is common to all three environments. The comparative analysis of the different study environments showed that the plots at the production stage and at the harvest stage are the most colonized by termites. Odontotermes sp. observed only in plots at the small stage, as well as Nasutitermes latifrons which are only present on the plot at the production stage. Pseudacanthotermes militaris are best represented on all three plots.
\end{abstract}

Keywords: Termite; Abundance; Attack; Cassava; Daloa; Côte d'Ivoire

\section{Introduction}

Cassava is a perennial shrub in the Euphorbiaceae family. Since its importance in Côte d'Ivoire during colonization, cassava and its derivatives have played a key role in the Ivorian economy and in the country's food security (FA0, [1]). It is an obvious source of wealth creation, sustainable income improvement, and a source of great hope among food crops. Cassava is one of the most important food crops in Côte d'Ivoire, with an estimated production of 4.54 million tonnes in 2016 and a consumption of 100-110 kg / year per capita living in urban areas (FA0, [1]). But despite numerous efforts to provide information, education, communication and awareness at the regional and national level, the production of this food remains insufficient. This insufficiency results in part from abiotic factors (climates, soils) and biotic factors such as crop enemies (Roy-noël [2]; Theberge [3]; Foua-Bi, [4]; Sere, [5]; Cissé [6]). Among the pests of cassava crops (Frappa [7]) are termites. They belong to the order of the Isoptera. It is termites that attack cultivated plants causing extensive damage and loss to crops. About $10 \%$ of termite species are considered to be pests (Wood [8]). Despite the many control methods used in Africa, it was contacted that the damage still persists and that crop losses are worsening each year. This situation results from the fact that no satisfactory method of phytosanitary protection has so

\footnotetext{
* Corresponding author: N'Guessan Lucie YEBOUE

Improvement and Agricultural Production Laboratory, UFR Agroforestry, Jean Lorougnon Guédé University, BP 150 Daloa, Côte d'Ivoire.
}

Copyright (C) 2021 Author(s) retain the copyright of this article. This article is published under the terms of the Creative Commons Attribution Liscense 4.0. 
far made it possible to contain or reduce appreciably the damage and its impact on the economy. Chemical control has mainly been used against these pests (Harris [9]; Wood and Pearce [10]). However, these products have been found to be dangerous for the environment, especially organochlorines (aldrin, dieldrin), the use of which has been regulated and even banned for certain products Akpesse et al. [11]. New substances have been tested, such as organo-phosphorus or, more recently, Fipronil (Bobe [12]). The general objective of this study is to ensure a sustainable productivity of cassava in the region of Daloa by controlling plague termites. Specifically, it will involve making an inventory of termites present in cassava plots, researching the phenological stages prized by termites, and determining the damage caused in these plantations.

\section{Material and methods}

\subsection{Study site}

The study was carried out at Jean Lorougnon Guédé University, located in the department of Daloa, Haut-Sassandra region in west-central Côte d'Ivoire. The town of Daloa is located at $6^{\circ} 53$ 'north latitude and $6^{\circ} 27^{\prime}$ west longitude of the Côte d'Ivoire. It is $141 \mathrm{~km}$ from Yamoussoukro. The Haut-Sassandra region is dominated by vegetation largely made up of dense forest. The relief is made up of plains with a ferralitic type soil. The climate is characterized by an equatorial and subequatorial regime with two rainfall maxima with four seasons. The main rainy season lasts from April to midJuly, peaking in June. The short dry season runs from mid-July to mid-September. The short rainy season runs from midSeptember to November with a peak in September while the long dry season lasts from December to March (N'Guessan et al. [13]). These two maxima are separated by one or two more or less rainy months (Brou [14]). The dry and wet seasons alternate with temperatures ranging from $24.65^{\circ} \mathrm{C}$ to $27.75^{\circ} \mathrm{C}$ on average (N'Guessan et al. [13]).

\subsection{Methodology}

In this study, six transects $(25 \mathrm{~m} \times 2 \mathrm{~m})$ were installed in the plots (two transects per plot). The age of the plots varies according to the different phenological stages (small stem stage, tuber production stage and tuber harvest stage). The plot at the small stem stage is located in Tapeguhé and is $2500 \mathrm{~m}^{2}$, the one at the production stage is located at the University and is $600 \mathrm{~m}^{2}$ and the plot at the harvest stage is also located at the University and is $600 \mathrm{~m}^{2}$. The termites from the cultivated medium were sampled using the transect technique recommended by Jones and Eggleton [15]. It consists of delineating 5 sections of $10 \mathrm{~m}^{2}(5 \mathrm{~m} \mathrm{x} 2 \mathrm{~m})$ in area along a $25 \mathrm{~m}$ long and $2 \mathrm{~m}$ wide transect in each plot. To do this, in each section litter and biogenic structures on the ground and above the ground, up to $1.5 \mathrm{~m}$ in height, are searched for termites. The harvested termites are stored in labeled pill boxes containing 70 pc alcohol (Figure 1).

\begin{tabular}{|c|c|c|c|c|}
\hline$*$ & $*$ & $*$ & $*$ & $*$ \\
\hline$*$ & $*$ & $*$ & $*$ & $*$ \\
\hline$*$ & $*$ & $*$ & $*$ & $*$ \\
\hline$*$ & $*$ & $*$ & $*$ & $*$ \\
\hline$*$
\end{tabular}

Figure 1 Diagram of the sampling plant by plant

\subsection{Identification and classification of termite damage on plants}

This identification was made by the random choice of one hundred (100) cassava plants attacked and numbered as indicated above on each plot. Three types of damage were categorized during this study. Classification is based on the progression of termites from superficial anatomical structures to deeper ones on the plant: bark, sapwood and heartwood. Type 1 (D1) damage is characterized by harvest (or prospecting) veneers which are food recognition veneers. Type 2 (D2) damage is defined by extensive coverage of the stems by harvest veneers and the establishment of termites in the sapwood and abundance of harvesters. Type 3 (D3) damage is characterized by the passage of termites from the sapwood to the heartwood with decomposition of the trunk for plants at the harvest stage.

The intensity values of the attacks were calculated and transcribed in a table (Table 1) as follows:

\section{$I=(N P A x 100) / N P O$}


I: Damage intensification index per plot; NPA: Number of plants attacked; NPO: Number of plants observed

\subsection{Analysis of the termite population structure}

The relative abundance of termites in the transect is the total number of encounters of species i collected in the transect divided by the total area of the sections. It is based on the incidence (presence $=1$ and absence $=0$ ) of the species considered. $\mathbf{A}=\mathbf{\Sigma} \mathbf{n i} / \mathbf{N}$; $\mathbf{n i}=$ incidence of individual of species $\mathbf{i}$ in the transect; $\mathbf{N}=$ total number of sections of the transect multiplied by the area of a section $\left(10 \mathrm{~m}^{2}\right)$ in a given environment. The relative abundance of termites between plots was compared using one-way analysis of variance (ANOVA) and the groups formed were separated using Fisher's LSD test at the $\mathrm{p}<0.05$ level. This analysis was performed using Statistica software (version 7.0).

The specific diversity can be approximated by a diversity index reflecting both the specific richness and the abundance of different species. The Shannon index (H') takes into account the number of taxa found on a plot (Magurran [16]).

$\mathbf{H}^{\prime}=-\boldsymbol{\Sigma} \mathbf{p i} \mathbf{x} \log \mathbf{2}(\mathbf{p i}), \mathbf{p i}=$ probability of encountering species $\mathbf{i}$; when $\mathrm{H}^{\prime}$ tends to 0 , the diversity is minimal. It is maximum when it tends towards $\mathrm{H}^{\prime}=5$. Fairness $(\mathbf{E})$ also called regularity, a measure of the equitable distribution of species. It makes it possible to compare populations with different numbers of taxa. Its objective is to observe the balance of the populations present. $\mathbf{E}=\mathbf{H} ' / \log 2(\mathbf{s})$. E tends towards 0 when the taxon dominates a stand and is equal to 1 when all the taxa have the same abundance.

The Simpson (D) index (Morin and Findlay [17]) assesses the probability that two individuals, drawn at random from an infinite population of $\mathrm{N}$ individuals, belong to the same species. In this study, the index "derived" from the Simpson's index is used (IS). With: IS = 1-D. The Simpson index varies between 0 and 1 . The diversity is minimum for $\mathbf{D}=\mathbf{1}$ and maximum for $\mathbf{D}=\mathbf{0}$. All these indices were calculated with R software (version 2.8) (Ihaka and Gentleman, [18]).

The Sørensen Similarity Index or Sørensen Similarity Coefficient (Qs) (Magurran [16]) was used to calculate the number of similar genera between the different plots studied. It is expressed by the following formula: Qs = 2c / (a + b); $\mathbf{a}$ : number of species mentioned in plot $1 ; \mathbf{b}$ : number of species described in plot 2. $\mathbf{c}$ : number of species common to both plots.

\section{Results}

\subsection{Diversity of the different study plots}

In total, three phenological stages were identified and prospected. The specific richness of termites varied according to the phenological stage of the cassava plots (Table 1). Four (4) species of termites were observed in the plot at the production stage, two (2) species in the plot at the small stage and two in the plot at the stage. The highest Shannon diversity index value was observed in the plot at the production stage $(0.88)$ followed by plots at the small stem stage and at the harvest stage with respectively $\mathrm{H}^{\prime}=0.62$ and $\mathrm{H}^{\prime}=0,61$. Fairness varied little. The highest value was observed in the plot at the small stage ( $\mathrm{E}=0.99)$, it was followed in the plot at the harvest stage $(\mathrm{E}=0.80)$. The production stage had recorded $E=0.63$ and constitutes the least balanced phenological stage. The Simpson index was high in the plot at the harvest stage $(\mathrm{SI}=0.61$ ). The lowest value was observed in the plot at the production stage $\mathrm{I}=0.48$ and the intermediate value was reported in the plot at the small stalk stage (IS $=0.49$ ).

Table 1 Diversity of plots according to phenological stages

\begin{tabular}{|c|c|c|c|c|c|c|c|c|c|}
\hline \multirow[t]{2}{*}{ Indices } & \multicolumn{3}{|c|}{ Small stem } & \multicolumn{3}{|c|}{ Production } & \multicolumn{3}{|c|}{ Harvest } \\
\hline & SR & $\mathbf{P}$ & $\mathbf{H a}$ & SR & $\mathbf{P}$ & Ha & SR & $\mathbf{P}$ & Ha \\
\hline $\mathrm{H}^{\prime}$ & 0,62 & - & - & - & 0,88 & - & - & - & 0,61 \\
\hline $\mathrm{E}$ & 0,99 & - & - & - & 0,63 & - & - & - & 0,80 \\
\hline IS & 0,49 & - & - & - & 0,48 & - & - & - & 0,61 \\
\hline
\end{tabular}

\subsection{Specific wealth of the plots}

In total, four (4) species of termites (Table 2) were identified in the three (3) cassava plots (Odontotermes sp., Macrotermes bellicosus, Pseudacanthotermes militaris and Nasutitermes latifrons). The species Pseudacanthotermes 
militaris is present in the three plots surveyed. Two species namely Odontotermes sp. and Pseudacanthotermes militaris were sampled in cassava plots at the small stalk stage and at the tuber production stage. As for the species of Macrotermes bellicosus, they were sampled in the plots in production and during harvest. Nasutitermes latifrons is the species which was sampled only in the plot at the tuber production stage.

Table 2 List of termites present on plants

\begin{tabular}{|l|l|l|c|c|c|}
\hline Families & Subfamilies & Espèces & Ss & Prod & Ha \\
\hline Termitidae & Macrotermitinae & Odontotermes sp. & $*$ & $*$ & \\
\hline & & Macrotermes bellicosus & & $*$ & $*$ \\
\hline & Pseudacanthotermes militaris & $*$ & $*$ & $*$ \\
\hline & Nasutitermes latifrons & & $*$ & \\
\hline TOTAL & 2 & 4 & 2 & 2 \\
\hline
\end{tabular}

\subsection{Relative abundance of termites in plots}

The relative abundance of termites by plot and by phenological stage was carried out. Overall, mean abundances vary widely. The lowest value is recorded in the cassava plot at the small stalk stage (1.8 individuals / $\mathrm{m}^{2}$ ) and the highest is 7.20 individuals $/ \mathrm{m}^{2}$ obtained in the plot at the harvest stage (Figure 2). Fisher's LSD test indicates that the relative abundance observed at the small stalk stage differs significantly from that recorded at the tuber production stage. Likewise, a significant difference was observed between the relative abundance obtained at the tuber production stage and that at the harvest stage $(\mathrm{p}<0.05)$.

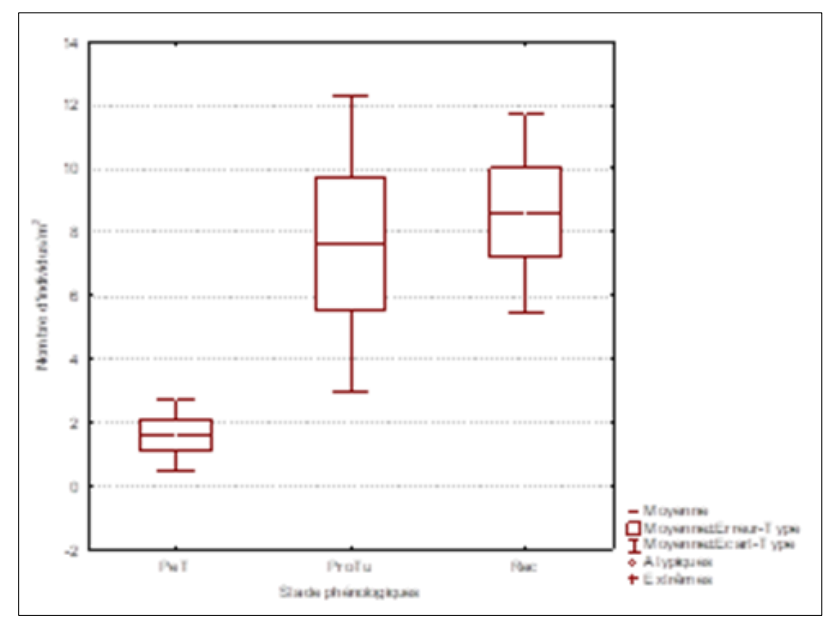

Figure 2 Relative mean abundance of the different phenological stages

Significant tests marked at $\mathrm{p}<0.05$; the means followed by the same letter are not significantly different (Fisher LSD test, $\alpha=0.05)$. PeT: small rod; ProTu: tuber production; Rec: harvest

\subsection{Termite attacks on plants according to the phenological stage}

Three types of damage were recorded during this study (Figure 3). However, the damage that could seriously affect cassava plants was mainly recorded at the tuber production and harvest stages. 


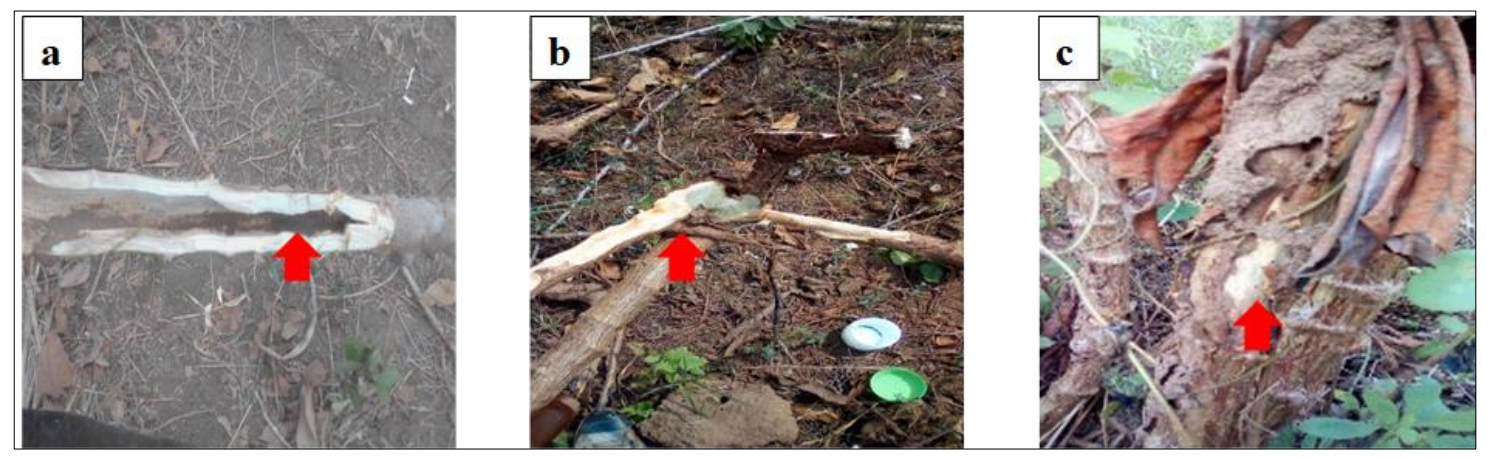

a: type 1 damage (D1), b: type 2 damage (D2) and c: type 3 damage (D3)

Figure 3 The different types of damage

\subsection{Proportion of attacks according to the phenological stage}

There is a large variation in the proportion of damage types depending on the phenological stages. Thus, on the small stem stage plot, type 1 (D1) damage was the most abundant (64\%), followed by type 2 (D2) and type 3 (D3) with respectively $27 \%$ and $9 \%$ (Figure $4 \mathrm{a}$ ). At the tuber production stage, only two types of damage were observed. In particular, type 1 (D1) damage with 63\% presence and type 2 (D2) with $37 \%$ presence (Figure $4 \mathrm{~b}$ ). The harvest stage presented the three types of damage. Type 1 damage (D1) with 56\% presence. They are followed by type 3 (D3) and type 2 (D2) damage with $5 \%$ and $39 \%$ presence respectively (Figure 4c).

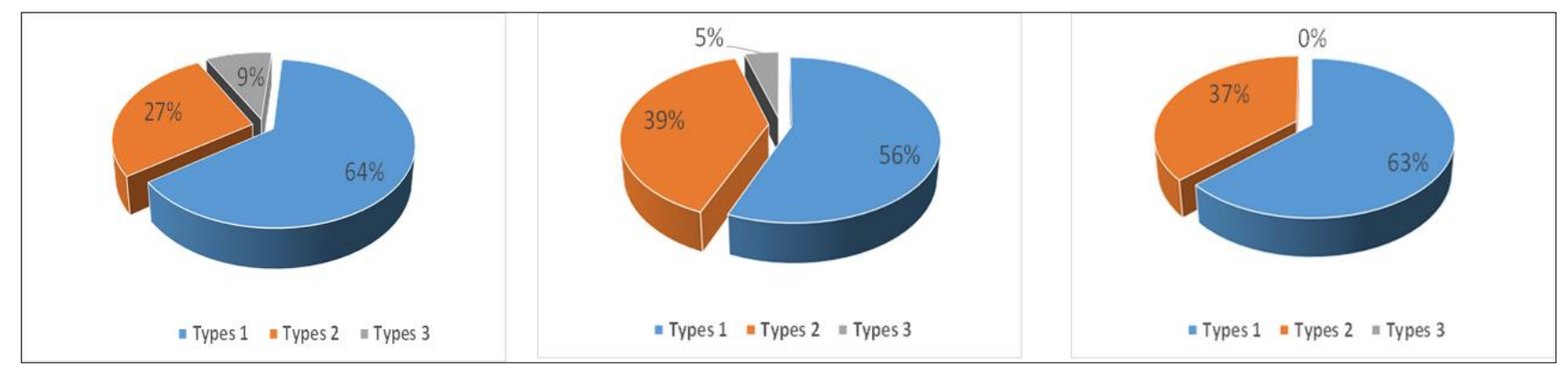

A: Small stem stage; b: Production stage; c: Harvest stage

Figure 4 Distribution of damage types in the study plots

\subsection{Intensity of termite attack on plants}

Of all the phenological stages, the harvest stage was the most attacked with $100 \%$ presence. On the other hand, the least affected was the small stem stage ( $5 \%$ presence). The plot at the tuber production stage was seriously affected by termites (70\% presence) (Table 3).

Table 3 Proportions of cassava plants attacked according to the phenological stage

\begin{tabular}{|l|c|c|c|c|}
\hline Phenological stage & NPO (\%) & NHF (\%) & NFA (\%) & I (\%) \\
\hline Small rod & 100 & 95 & 5 & 5 \\
\hline Tuber production & 100 & 30 & 70 & 70 \\
\hline Harvest & 100 & 00 & 100 & 100 \\
\hline
\end{tabular}

NPO: Number of plants observed; NHF: Number of healthy feet; NFA: Number of feet attacked; I: Intensity

\section{Discussion}

In total, four species of termites were collected from all three plots studied. This result shows a low specific richness in termites of the studied plots. This could be linked to the monoculture observed in the different plots. Other observations were made on other monocultures in Togo, particularly in teak plantations in the Etô and Noèpé classified forest by Gbenyédji et al. [19] and in the sugar cane plantations of Kévé, Tchikplonou Condji by Anani et al. [20] where the first 
author obtained five (5) and ten (10) species of termites and the second obtained seven (7) and three (3) species of termite respectively. Leaves and roots as a whole have not been visited by termites, whereas the stem has. This preference for stems by termites of the Macrotermitinae group has already been pointed out by several authors. Akpesse et al. [11] report Pseudacanthotermes attack on maize stalks in Booro-Borotou (Côte d'Ivoire). This affinity could be justified by the probable difference in the content of cellulose, the main food source for these organisms.

From the three phenological stages (small stem, production and harvest) it appears that the plot at the harvest stage was clearly more exploited. The heavy exploitation at this stage can be explained by the presence of an abundant food source in the immediate environment which would attract termites (Ahmed et al. [21]). It should be noted that at the stage harvest all the stems strewn on the ground. Termites, living in the soil, thus have easy and quick access. This plot is said to be devoid of the ants Pachycondyla analis and Centromyrmex sellaris, specialists in termite predation (Yeo [22]). Of all the plots, that of the harvest stage was the most exploited. No doubt, because of the presence of substances which would attract termites. Termite attacks on the mango tree have been observed by Han and N'Diaye [23] in Senegal. These authors showed that $66.8 \%$ (out of a total of 600 mango trees) were attacked by termites. The massive exploitation of cola leaves is contrary to our expectations. The literature nowhere mentions the attack of termites on this plant although prospecting activities are sometimes observed on the trunk. Unlike the leaves of the colatier, those of the mango tree were much less visited (4.76\%). This would be linked to the repellent effect exerted by the high concentrations of odoriferous compounds (Kpemissi, [24]) on the harvesting colonies. Termite stand of all cassava fields revealed 4 species (Odontotermes sp., Macrotermes bellicosus, Nasutitermes latifrons and Pseudacanthotermes militaris). All these species have already been reported in different environments in Côte d'Ivoire (Bodot [25]; Josens, [26]; Sangaré and Bodot [27]; Kouassi, [28])

The high rate of infestation of cassava fields at the production and harvest stages is believed to be due to reduced maintenance of plots and non-use of phytosanitary products due to the lack of purchasing power of the farmers. Nasutitermes latifrons although not reported in the literature as a pest of cassava, is presented by Santos et al. [29] as being a real danger for this plant for the cocoa tree. It builds tree nests there (Santos et al., [29]). It attacks older plants preferentially through harvest veneers. They penetrate the first barrier of bark by puncturing it and then into the sapwood and heartwood, usually causing Type 3 damage. Overall, these attacks could be influenced by environmental factors such as daily variations in temperature, predators such as ants, parasites and relative humidity of plots (Pearce, [30]). In addition, there are the human factors of poor agricultural practices (cuts and wounds of the feet) (Tra bi et al., [31]).

Attacks that can lead to reduced production and plant death are caused by damage types 2 and 3. Pseudacanthotermes has been reported to be a pest of cassava plants. Akpesse et al. [11] presents it as a formidable pest of food crops. These termites prey on the desiccated terminations of cut suckers. They spread down these and gain access to healthy trunks. The low presence of termites on the plot at the small stage could be justified by the regular weeding of the plot, greatly reducing the food source in the immediate environment which would attract termites (Ahmed et al. [21]). Among the cassava pest termites identified, the genus Pseudacanthotermes acts "disastrously". Crop veneers are very often absent on the cassava trunk although infestations are advanced. These termites establish galleries and chambers inside the bulb, causing the plant to die. According to Sands [32], the best way to reduce attacks is to maintain the plots.

\section{Conclusion}

This study revealed that among the four (4) species of termite encountered in the three cassava plots surveyed, only 1 species (Pseudacanthotermes militaris) is common to the three plots. The cassava plot at the production stage contains more species than the other plots. It has shown that termite disease varies according to the phenological stage of the cassava plots studied. It is high in the plots at the production and harvest stage, and low in the plots at the small stem stage. The study also showed that the age of the fields would influence the activity of different trophic groups. Thus, the activity of Odontotermes, Nasutitermes and Macrotermes decreases with age while that of Pseudacanthotermes increases with age. Analysis of the relative abundances of termite species revealed that the abundance increases with the phenological stage of the plots. Pseudacanthotermes militaris termites are abundant. Their abundance is very high in the plot at the harvest stage. This study also provided insight into the damage that termites could cause at the 3 phenological stages (small stem, production and harvest). This study also made it possible to characterize three types of damage, the proportions of which vary from one phenological stage to another. It will therefore allow the establishment of a better system to fight against cassava termites according to the different stages. 


\section{Compliance with ethical standards}

\section{Acknowledgments}

We would like to thank the authorities of Jean Lorougnon Guédé University as well as the notability of the Tapeguhé village who facilitated access to the study sites.

\section{Disclosure of conflict of interest}

The author declares no conflict of interest.

\section{References}

[1] FAO. In Côte d'Ivoire, zero hunger in 2030 is possible. 2008.

[2] Roy-noël J. Research on the ecology of Isoptera from the Cape Verde peninsula (Senegal). II. - Species and their ecology. Bull. IFAN, sér. A, T. 1974; 36(3): 527-609.

[3] Theberge RL. The main pests and diseases of cassava, yam, sweet potato and Araceae in Africa. Ibadan (Nigeria) IITA. 1985.

[4] Foua-bi K. The entomofauna of the rice fields of the Taï region (forest southwest of the Ivory Coast). In: Actes II. Yamoussoukro International Symposium, Côte d'Ivoire. The role of biology in solving the food crisis in Africa. ABN-UNESCO-BREDA, Dakar. 1989; 257-267.

[5] Sere Y. Corn streak and other diseases in Burkina Faso. In: Integrated pest control of food crops in the Sahel. Bamako, Mali, Sahel Institute. 1990; 276-284.

[6] Cissé M. Contribution to the study of corn (Zea mays) entomofauna and termite control. Diploma of Advanced Studies, University of Abidjan, Côte d'Ivoire. 1991.

[7] Frappa C. Insects harmful to growing cassava and cassava tubers in stores in Madagascar. Journal of applied botany and colonial agriculture. 1938; 18(197): 17-29.

[8] Wood TG. The role of termites (Isoptera) in decomposition processes. In: (Ed.), M. Anderson and Macfadyen. The role of terrestrial and aquatic organisms in decomposition processes. Blackwell, Oxford. 1976; 145-168.

[9] Harris WV. Termites as pests of crops and trees. Commonwealth Institute of Entomology, London. 1969.

[10] Wood TG, Pearce MJ. Termites in Africa: the environmental impact of control measures and damage to crops, trees, rangeland and rural buildings. Sociobiology. 1991; 19: 221-234.

[11] Akpesse AA, Kouassi KP, Tano Y, Lepage M. Impact of termites on farmers' rice and corn fields in the subSudanese savannah (Booro-Borotou, Côte d'Ivoire), Sciences and nature. 2008; 5(2): 121-131.

[12] Bobe A ate and behavior of the insecticide fipronil in soil. Study in a tropical environment (Niger) under locust control conditions. University Thesis, Montpellier I University. 1998.

[13] N'Guessan AH, N'Guessan KF, Kouassi KP, Kouamé NN, N'Guessan PW. Population dynamics of the cocoa stem borer, Eulophonotus myrmeleon, Felder (Lepidoptera: Cossidae) in the region of Haut-Sassandra in Côte d'Ivoire. Journal of Applied Biosciences. 2014; 83: 7606-7614.

[14] Brou TY. Climate, socio-economic changes and landscapes in Côte d'Ivoire. Synthesis of scientific activities for an Habilitation to Direct Research. University of Science and Technology of Lille, France. 2005.

[15] Jones DT, Eggleton P. Sampling termite assemblage in tropical forest: testing a rapid biodiversity assessment protocol. Journal of applied Ecology. 2000; 37: 191-203.

[16] Magurran AE. Measuring Biological Diversity. Blackwell publishing. 2004.

[17] Morin A, Findlay S. Biodiversity: Trend and process. Biology of Species Conservation. University of Ottawa, Canada. 2001.

[18] Ihaka R, Gentleman R. R: A language for data analysis and graphics. Journal of Computational and Graphical Statistics. 1996; 5: 299-314. 
[19] Gbenyedji JN, Kotoklo EA, Amevoin K, Glitho IA. Specific diversity of termites (Isoptera) in two teak plantations (Tectona grandis L.) in southern Togo. International Journal of Biological and Chemical Sciences, 2011; 5(2): 755765.

[20] Anani KE, Nuto Y, Tano Y, Rouland-Lefèvre C, Bordereau C, Glitho AI. Termite stand in the sugar cane fields in Tchikplonou-Condji and Kévé, two localities in South Togo. Annals of the University of Lomé, 2008; 17: 79-95.

[21] Ahmed S, Khan RR, Hussain G, Riaz MA, Hussain A. Effect of Intercropping and organic matter on the subterranean termites population in sugarcane field. International Journal of Agriculture and Biology. 2008; 10(5): $581-584$.

[22] Yeo K. Spatial dynamics and diversity of litter and soil ants in the forest-savanna mosaic in Ivory Coast. Doctoral thesis, Paris VI University, France. 2006.

[23] Han S, N'Diaye A. Damage caused by termites (Isoptera) on fruit trees in the region of Dakar (Senegal). Acts Coll. Social insects. 1996; 10: 111-117.

[24] Kpemissi AE. The Anacardiaceae of Togo: Botanical, ecological studies and antifungal properties. Doctoral thesis, University of Lomé, Togo. 2007.

[25] Bodot P. Ecological and biological study of termites from the savannah of the lower Ivory Coast. Doctoral thesis in Sciences, University of Aix-Marseille, France. 1966.

[26] Josens G. Biological and ecological study of termites (Isoptera) of the Lamto-Pakobo savannah (Côte d'Ivoire). State Doctorate thesis, Free University of Brussels, Belgium. 1972.

[27] Sangare Y, Bodot P. Preliminary data on the termite fauna in tropical rainforests (Taï region, southwest of Côte d'Ivoire) Inventory, ethological and biological classification of the genera and species listed. Annals of the University of Abidjan, Series E. 1980; 13:123-141.

[28] Kouassi KP. 1999. Structure and dynamics of trophic groups of soil macrofauna in natural and transformed ecosystems of Côte d'Ivoire. State Science Thesis, University of Cocody-Abidjan, Côte d'Ivoire. 1999.

[29] Santos PP, Vasconcellos A, Jahyny B, Delabie JHC. Ant fauna (Hymenoptera, Formicidae) associated to arboreal nests of Nasutitermes spp. (Isoptera, Termitidae) in a cacao plantation in southeastern Bahia, Brazil. Revista Brasileira de Entomologia. 2010; 54(3): 450-454.

[30] Pearce M J. Termites: Biology and Pest Management. Wallingford CAB international, Publisher Cambridge University Press. 2007.

[31] Tra Bi CS, Soro S, Yéboué NL, Tano Y, Konaté S. Termites impact on different age of Cocoa (Theobroma cocoa L.) plantations with different fertilizer treatments in semi-deciduous forest zone (Oume, Ivory Coast). Herald Journal of Agriculture and Food Science Research. 2015; 4(4): 21-27.

[32] Sands WA. The role of termites in agriculture. Outloock on agriculture. 1977; 9: 136-143. 